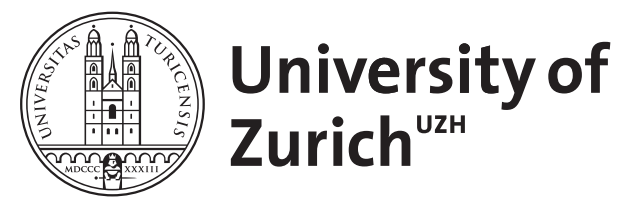

\title{
Medical Aspects of Mountain Rescue by Helicopter
}

\author{
Hossli, Georg ; Bühler, Christian
}

\begin{abstract}
In summer, mountain accidents may include falls, causing contusions and open wounds; fractures and torn ligaments; external bleeding;internal bleeding in the head, thorax and abdomen; injuries to the spinal column and extremities; falling rocks causing skull injuries; and falls into crevasses causing additional hypothermia, frostbite and drowning. In winter, there are skiing accidents with fractures and torn ligaments; and avalanches resulting in asphyxia, hypothermia and frostbite. In addition, there are mountain sickness; pulmonary edema of high altitude; snow blindness; heatstroke; sunstroke; heart attack; diarrhea and vomiting; pneumonia; snakebite; drowning in torrents or lakes; and burns, explosions and cuts acquired in huts. First aid, medical support and transport to hospital may vary widely.
\end{abstract}

DOI: https://doi.org/10.1017/s1049023x00032799

Posted at the Zurich Open Repository and Archive, University of Zurich ZORA URL: https://doi.org/10.5167/uzh-154909

Journal Article

Published Version

Originally published at:

Hossli, Georg; Bühler, Christian (1985). Medical Aspects of Mountain Rescue by Helicopter. Prehospital and Disaster Medicine, 1(01):70-71.

DOI: https://doi.org/10.1017/s1049023x00032799 
Olympic Games in Innsbruck, was very good.

The further development of powerful helicopters has made it possible to transport one or more persons at the same time, both rescuers and accident victims. Again, it was the Swiss Air Rescue Service which set an example in this field. They use the rescue rope and the horizontal net developed by Bühler. With this equipment an airborne rescuer can be set down and both he and the accident victim picked up again, even in the steepest terrain where there are no landing possibilities for a helicopter. The $8 \mathrm{~m}$ long rope is hooked to the bottom of the helicopter, with the rescue worker hanging from the other end in a harness.

Some rescue helicopters are also equipped with a built-in cable winch, which allows the rescue worker to leave the helicopter in flight and descend about twenty meters to the site of the accident. This air rescue method was adapted by the individual alpine countries to meet their particular demands. For example, in France the transport litter developed by Piguillem can be hauled up and loaded onto the Alouette III helicopter during flight. The Swiss Air Rescue Guard transports accident victims outside the helicopter when using both the rescue line and the cable winch, similar to our method in Austria. The accident victim is transported in a bag outside the helicopter to the next interim landing point, where he is loaded on board the helicopter.

Every rescue operation by means of rescue rope or cable winch demands intensive cooperation between the pilot and the air rescue worker, whereby radio contact between them is a necessity. In extreme rescue operations from steep rock walls, the rescue line and cable winch can be extended to $100 \mathrm{~m}$, although this requires a helicopter pilot with special experience in this particular rescue technique. In addition to technical skills and extreme concentration, any alpine air rescue operation calls for a high degree of idealism and commitment.
Georg Hossli, M.D., Christian Bühler, Ph.D. Zurich, Switzerland

In summer, mountain accidents may include falls, causing contusions and open wounds; fractures and torn ligaments; external bleeding;internal bleeding in the head, thorax and abdomen; injuries to the spinal column and extremities; falling rocks causing skull injuries; and falls into crevasses causing additional hypothermia, frostbite and drowning. In winter, there are skiing accidents with fractures and torn ligaments; and avalanches resulting in asphyxia, hypothermia and frostbite. In addition, there are mountain sickness; pulmonary edema of high altitude; snow blindness; heatstroke; sunstroke; heart attack; diarrhea and vomiting; pneumonia; snakebite; drowning in torrents or lakes; and burns, explosions and cuts acquired in huts. First aid, medical support and transport to hospital may vary widely.

The principles to be observed in mountain rescue are the same as elsewhere: immediate care is required when acute danger to life or

From the Institute of Anesthesiology, Zurich University, Canton Spital and the Swiss Air Rescue, Zurich, Switzerland. danger of serious lasting injury is suspected. Examples are polytrauma with injuries of body cavities, head, neck or spine and hemorrhagic shock, coma or somnolence, and patients with heart insufficiency. Such an emergency may require clearing of airways; correct positioning; endotracheal intubation; artificial ventilation; control of hemorrhage; treatment of shock; and cardiac resuscitation. In such situations, non-medical helpers may be life saving. In serious cases, help from a trained emergency physician is important provided it arrives in time. On the spot first aid (phase 1 of emergency medicine) by a non-medical helper and emergency physician must pave the way to recovery already on the spot and during transport. They are, so to speak, the "extended arm" of the surgeon, anesthesiologist or emergency internist. The various phases of preclinical care are linked like a chain, the Rescue Chain. Bearing in mind that chain is only as strong as its weakest link, it is obvious that only if each link works perfectly, will the patient arrive at the hospital in optimal condition. 
In the mountains, however, the realization of adequate first aid and transportation is often not possible due to remote accident site, bad weather, competent helpers and medical equipment not available in time, and long and difficult transport to shelter and hospital. It is obvious that the rescue helicopter offers the following advantages:

1) The emergency physician and specially trained rescuers, equipment for rescue, drugs, instruments and devices for extended first aid measures can be flown to the site of the accident, often even at night, with a speed of $100 \mathrm{knots}$ or $3 \mathrm{~km} / \mathrm{min}$. 2) Doctor and rescue specialist can be lowered to the injured person if there is no landing possibility, by means of the rescue winch, to otherwise inaccessible sites, such as crevasses, rock faces, gullies or steep wooded terrain. 3) Rescue of the patient, who is under constant supervision by the doctor is subsequently affected by means of the horizontal net, a device designed especially for this purpose. In this lightweight net, the patient can be winched up to the helicopter hovering overhead in a realtively stable position, either stretched out on his back or his side. 4) Optimal fixation of the patient is achieved on the vacuum mattress, an aid of particular benefit for patients with fractures and spine injuries. Such patients require careful pickup and relocation from net to stretcher or vacuum mattress. The dismountable and lightweight scoop stretcher is of great advantage. 5) Immediate care is effected by the emergency physician or the rescue specialist on the spot, before winching up. Medical first aid commences at once after rescue, near or inside the helicopter, in a sheltered and heated environment. 6) After the highrisk patient's condition has been stabilized, he can be transported to the most appropriate hospital, which need not be the nearest one.

7) Transportation is gentle, preventing added injury due to jolting, and under close supervision with uninterrupted therapy for respiratory and circulatory disorders.

Monitoring and treatment of the high risk patient can be carried out similar to care in the intensive care unit. The rescue helicopter is a flying ICU. Given the provision of such optimal care during transportation, the time required for the journey itself is no longer of primary importance.
In our country, the Swiss Air Rescue has built up a network of rescue bases and has rescue helicopters with trained pilots, emergency doctors and professional helpers stationed there or in hearby hospitals, all linked together through a network of 32 radio stations and more than 300 mobile radio sets. One emergency phone number for the entire country connects callers with headquarters, where specialized personnel are on duty around the clock. The organization of this air rescue system and the location of its bases permit any point in Switzerland to be reached withn 15 minutes' flight time. Transport operations of injured or acutely ill persons in mountainous regions, formerly carried out on the ground by means of alpine rescue teams and frequently an extremely difficult and time-consuming affair, can today be effected by rescue helicopter, usually within 30 minutes, even under the most difficult of conditions, with optimal patient handling and treatment. Medical centers have floodlit landing pads near the emergency department.

In 1980, the Swiss Air Rescue flew 1192 emergency missions in the Swiss mountains, rescued 1098 patients, and recovered, 106 dead bodies. The sharp increase in the number of missions carried out over the past 20 years, since the foundation of the SAR, from 130 in 1961 to 3866 in 1980 (including flights from smaller hospitals to medical center, and traffic accident missions), indicates that this service is becoming an increasingly important component of the overall rescue system in our country. 